\title{
Presence of Human Antibodies Reacting with Candida albicans O-Linked Oligomannosides Revealed by Using an Enzyme-Linked Immunosorbent Assay and Neoglycolipids
}

\author{
MARIE PIERRE HAYETTE, ${ }^{1}$ GÉRARD STRECKER,${ }^{2}$ CHRISTINE FAILLE, ${ }^{1}$ DANIEL DIVE, ${ }^{1}$ \\ DANIEL CAMUS, ${ }^{1}$ DONALD W. R. MACKENZIE, ${ }^{3}$ AND DANIEL POULAIN ${ }^{1 *}$ \\ Institut National de la Santé et de la Recherche Médicale, Unité 42, Domaine du CERTIA, 369, rue J. Guesde. \\ BP 39, and Laboratoire de Chimie Biologique et Unité Mixte 111 CNRS, Université des Sciences et Techniques \\ de Lille Flandres-Artois, 59650 Villeneuve d'Ascq, France, and Mycological Reference Laboratory, \\ Central Public Health Laboratory Service, London NW9 5HT, United Kingdom ${ }^{3}$
}

Received 24 July 1991/Accepted 24 October 1991

\begin{abstract}
In order to study the presence of antibodies directed against Candida albicans O-linked oligomannosides (oligomannosides 0 ) in patient sera, we have developed an enzyme-linked immunosorbent assay (ELISA) involving neoglycolipids constructed with these residues (NGLO). Oligomannosides $O$ released by mild alkaline degradation of the $C$. albicans cell wall phosphopeptidomannan (PPM) contained one to seven mannose residues, among which the quantitatively major components, mannobiose and mannotriose, were shown by ${ }^{1} H$ nuclear magnetic resonance to contain exclusively $\alpha(1-2)$ linkages. The pool of oligomannosides was converted to neoglycolipids by coupling them to 4-hexadecylaniline in an equimolar reaction checked by thin-layer chromatography. We have tested against these neoantigens, coated on ELISA plates, 15 pairs of sera corresponding to individual seroconversions observed in $\mathbf{1 5}$ patients during the course of a mycological and serological survey of candidiasis. For all patients, seroconversions resulted in an increased level of antibodies against NGLO. A significant correlation was observed between the results of ELISA-NGLO, ELISA involving the original PPM molecule, and routine antibody detection tests, indirect immunofluorescence assay, and cocounterimmunoelectrophoresis. These results therefore demonstrate the synthesis of human antibodies reactive with oligomannosides $\boldsymbol{O}$ constitutive of the $\boldsymbol{C}$. albicans mannan molecule which have been previously described as exhibiting an inhibitory effect on human lymphocytic proliferation.
\end{abstract}

Candida albicans mannan polysaccharide is a major component of the cell wall whose importance in the physiopathology of candidiasis has been the subject of extensive studies. It has been shown that mannans determine the antigenic specificity of Candida species and $C$. albicans serotypes as analyzed with polyclonal-adsorbed antibodies $(11,29)$. Antimannan antibodies are present in the sera of most healthy individuals (2) and show an increase during development of invasive candidiasis in immunocompetent patients (15). Furthermore, antimannan polyclonal (1) or monoclonal $(10,19)$ antibodies allow the detection of antigenemia in sera from patients with systemic Candida infection. Finally, bioclinical and experimental evidence indicates that mannan is a potent immunomodulator (4).

Recent refinements in methods for fractionation and structure determination have led to the description of a model for the structure of these cell wall matrix components extracted by autoclaving and corresponding to phosphopeptidomannan (PPM) $(12,25,26)$. The polysaccharide moiety of the PPM molecule is linked to the peptide via asparagine $(N$ glycoside part) and serine or threonine residues $(O$-glycoside part). The $N$-glycoside part is composed of a highly branched chain of mannopyrannosyl residues linked by $\alpha(1-6)$ bonds to which are attached oligosaccharide side chains, where mannopyrannosyl residues are linked through $\alpha(1-2), \alpha(1-3), \beta(1-2), \beta(1-6)$, and phosphodiester bonds $(7,8$, $12,14)$. The $O$-glycoside component appears to consist of shorter and unbranched chains (18).

\footnotetext{
* Corresponding author.
}

Experimental evidence indicates that individual oligomannosides obtained by depolymerization of the PPM molecule represent epitopes which have been described as the basis of rabbit polyclonal-antibody specificities $(7,28)$. These conclusions were reached by application of inhibition reactions in liquid phase $(7,8,17)$. These techniques, which are not well adapted to the multivalent character of immunoglobulin M (IgM), the predominant isotype against polysaccharides, require large quantities of purified oligomannosides and are poorly adapted to extensive screenings. At the moment, because of the lack of appropriate methodology, recognition by human antibodies of the $C$. albicans oligomannoside repertoire present in the mannan molecule is virtually unknown. We have recently developed a method to render oligomannosides antigenic by coupling them to a carrier molecule able to bind to a conventional substrate for immunoanalysis $(5 a, 6)$. The oligomannosides are coupled to a lipid, 4-hexadecylaniline, according to a method leading to a mole-to-mole binding whose efficiency can be vizualized and assessed after thin-layer chromatography. The purpose of this work was to use this method to determine if the O-linked oligomannosides, which have been recently demonstrated as exhibiting an inhibitory effect on human lymphocytic proliferation induced by Candida and other antigens (18), elicit an antibody response during invasive candidiasis.

O-linked oligomannosides, released from the PPM molecule by $\beta$ elimination, were analyzed by thin-layer chromatography and ${ }^{1} \mathrm{H}$ nuclear magnetic resonance (NMR) (for the two major oligomannosides) before being converted to neoglycolipids (NGL) containing O-linked oligomannosides (NGLO). NGLO were coated on plates for an enzyme-linked 
TABLE 1. Identification of sera from 15 patients tested with ELISA procedures against PPM and NGLO

\begin{tabular}{|c|c|c|c|c|c|}
\hline $\begin{array}{l}\text { Patient } \\
\text { no. }\end{array}$ & Service & $\begin{array}{l}\text { Source of } \\
\text { Calbicans }\end{array}$ & Serum $^{a}$ & IFA titer & $\begin{array}{l}\text { Co-CIE } \\
\text { score }^{b}\end{array}$ \\
\hline \multirow[t]{2}{*}{1} & Intensive care & Hemoculture & D-2 & 200 & $\mathbf{0}$ \\
\hline & & & $D+5$ & 1,600 & 7 \\
\hline \multirow[t]{2}{*}{2} & Intensive care & Biopsy & $D-5$ & 50 & 0 \\
\hline & & & $D+7$ & 400 & 6 \\
\hline \multirow[t]{2}{*}{3} & Surgery & $\begin{array}{l}\text { Pleural extrava- } \\
\text { sation }\end{array}$ & D-1 & 100 & $\mathbf{0}$ \\
\hline & & & $D+24$ & 400 & 6 \\
\hline \multirow[t]{2}{*}{4} & Surgery & Drain & $D-30$ & 100 & 0 \\
\hline & & & D-8 & 800 & 5 \\
\hline \multirow[t]{2}{*}{5} & Surgery & Pancreatic liquid & D-37 & 100 & 3 \\
\hline & & & $D+4$ & 400 & 5 \\
\hline \multirow[t]{2}{*}{6} & Surgery & Hemoculture & D-30 & 50 & $\mathbf{0}$ \\
\hline & & & $\mathrm{D}-1$ & 400 & 5 \\
\hline \multirow[t]{2}{*}{7} & Intensive care & Bronchial liquid & $D-26$ & 100 & 0 \\
\hline & & & $D+5$ & 400 & 5 \\
\hline \multirow[t]{2}{*}{8} & Surgery & Peritoneal liquid & D-1 & 100 & 0 \\
\hline & & & $D+14$ & 800 & 7 \\
\hline \multirow[t]{2}{*}{9} & Intensive care & Peritoneal liquid & $D-1$ & 200 & 0 \\
\hline & & & $D+6$ & 800 & 6 \\
\hline \multirow[t]{2}{*}{10} & Surgery & Urine & $D-15$ & 50 & $\mathbf{0}$ \\
\hline & & & $D+2$ & 400 & 5 \\
\hline \multirow[t]{2}{*}{11} & Intensive care & Urine & $D-2$ & 200 & 4 \\
\hline & & & $D+6$ & 800 & 6 \\
\hline \multirow[t]{2}{*}{12} & Urology & Urine & $D-7$ & 200 & $\mathbf{0}$ \\
\hline & & & $D+6$ & 800 & 4 \\
\hline \multirow[t]{2}{*}{13} & Intensive care & Urine & $D-34$ & 50 & 0 \\
\hline & & & $D+50$ & 800 & 6 \\
\hline \multirow[t]{2}{*}{14} & Intensive care & Urine & D-1 & 100 & $\mathbf{0}$ \\
\hline & & & $D+9$ & 1,600 & 5 \\
\hline \multirow[t]{2}{*}{15} & Urology & Urine & $D-60$ & 200 & 4 \\
\hline & & & $D-3$ & 800 & 6 \\
\hline
\end{tabular}

${ }^{a}$ Identification of sera relates to the date of serum sampling in relation to mycological examination. $\mathrm{D}$, day; + or -, before or after positive culture.

${ }^{b}$ Defined as follows: 0 , absence of precipitin line; 1 , faint, nonspecific precipitin line; 2 , one nonspecific precipitin line; 3 to 7 , presence of cospecific precipitin line with increasing intensities.

immunosorbent assay, and their antigenicity was studied by probing them with human sera. These sera were retrospectively selected from hospital inpatients who had seroconverted during the course of a mycological and serological survey for candidiasis by indirect immunofluorescence assay (IFA) and cocounterimmunoelectrophoresis (Co-CIE) procedures (20). The results of ELISA-NGLO appeared to correlate with the results of ELISA involving the original PPM molecule and with results from routine serological tests. Construction of NGL has provided, for the first time, evidence for the synthesis of antibodies against O-linked oligomannosides.

\section{MATERIALS AND METHODS}

Strain. A cloned strain of $C$. albicans serotype A (VW 32) was used throughout this study. It was selected because of its high reactivity against sera from patients suffering from candidiasis (21).

Human sera. Details for these sera are given in Table 1. Thirty sera originated from 15 patients who were retrospectively selected according to biological and clinical data collected in the department of Parasitology-Mycology at the University Hospital of Lille. The following selection criteria were applied: (i) patients who had had $C$. albicans isolated at least once in large quantities from normally sterile sites (including blood, catheter, drain, peritoneal and pleural cavities, biopsies, and pancreatic cyst) or from urine samples; (ii) patients with probable invasive candidiasis, based on history and presentation (fever resistant to antibiotics, response to antifungal therapy); (iii) availability of serial serum samples for the corresponding patients taken near the date of positive cultures and demonstrating seroconversion as analyzed by routine serodiagnostic procedures (IFA and Co-CIE; see below). Two sera were selected for each of the 15 patients: one from before and one from after seroconversion. As a positive control (C), we used the serum from a patient who had presented with $C$. albicans septicemia proved by three successive positive blood cultures and who exhibited high levels of antibody against $C$. albicans.

Routine serological tests. (i) IFA. IFA was performed with C. albicans VW 32 blastoconidia (20). Standardization of this test was achieved by the use of a pool of sera from patients with candidiasis (Bio-Mérieux, Marcy l'Etoile, France). A titer equal to or greater than $\mathbf{4 0 0}$ is considered indicative of candidiasis.

(ii) Co-CIE. Co-CIE with a soluble extract of VW 32 blastoconidia was used to detect precipitating antibodies presenting a line of identity with an anti-VW 32 germ tube antiserum (20). This line of identity is named the cospecific precipitin line (CSPL). Interpretation of Co-CIE results refers to presence or absence of CSPL and quantitative evolution of the CSPL (migration towards the cathode which increases in intensity for successive sera from the same patients). Quantification of the results obtained by Co-CIE was needed for statistical analysis, and results were expressed through scores defined as follows: 0 , absence of precipitin line; 1 , faint, nonspecific precipitin line; 2 , one nonspecific precipitating line; 3 to 7 , presence of CSPL with increasing intensities.

Obtainment and analysis of O-linked oligomannosides. (i) Production of PPM. PPM was extracted from yeast cells grown in bioreactors according to the method described by Kocourek and Ballou (13). The procedure was modified in that a single extraction in citrate buffer was made (6).

(ii) Mild acid hydrolysis. According to the method of Faille et al. (6), $1 \mathrm{~g}$ of PPM was dissolved in $50 \mathrm{ml}$ of $\mathrm{HCl}(0.01 \mathrm{~N})$, and the solution was heated at $100^{\circ} \mathrm{C}$ for $30 \mathrm{~min}$. After cooling, the solution was neutralized with $\mathrm{NaOH}$ and lyophilized.

(iii) Mild alkaline hydrolysis. According to a method adapted from that of Nakajima and Ballou (16), $585 \mathrm{mg}$ of PPM depleted of oligomannosides after mild acid hydrolysis was dissolved in $50 \mathrm{ml}$ of $\mathrm{NaOH}(0.1 \mathrm{~N})$, incubated for $24 \mathrm{~h}$ at $25^{\circ} \mathrm{C}$ under agitation, and then neutralized with acetic acid (1 N) and lyophilized.

(iv) Gel filtration chromatography. After each hydrolysis, the products were dissolved in water and settled on Bio-Gel P4 (Biorad, Herdfordshire, England) columns (1.8 by 150 $\mathrm{cm})$. The columns were eluted with distilled water at a flow rate of $5 \mathrm{ml} / \mathrm{h}$ at room temperature. Fractions $(2 \mathrm{ml})$ were collected and analyzed by thin-layer chromatography.

(v) Thin-layer chromatography. The oligosaccharides were separated on Silica Gel 60-precoated plates (Kieselgel 60, Merck, Darmstadt, Germany) with $n$-butanol-acetic acidwater $(20 / 10 / 10, \mathrm{vol} / \mathrm{vol} / \mathrm{vol})$ as a solvent. The oligosaccharides were stained with a solution of orcinol $(2 \mathrm{~g} /$ liter $)$ in $20 \%$ sulfuric acid and heated at $105^{\circ} \mathrm{C}$ for $10 \mathrm{~min}$. NGL were settled on Silica Gel 60 F254-precoated plates (DC Alufolien 60 F254 Kieselgel, Merck) and separated with chloroformmethanol-water $(54 / 34 / 9.3, \mathrm{vol} / \mathrm{vol} / \mathrm{vol})$ as a solvent. Lipids (free and included in NGL) were detected on the thin-layer 
chromatography plates by short-wave (254-nm) UV light. The glycan moiety was stained by orcinol sulfuric reagent.

(vi) ${ }^{1}$ H NMR analysis. The solution of oligomannosides was exchanged several times in $\mathrm{D}_{2} \mathrm{O}$ with intermediate lyophilization. NMR spectral analysis of the compounds in $\mathrm{D}_{2} \mathrm{O}$ (99.95\%; Commissariat à l'Energie Atomique, Gif sur Yvette, France) was carried out on a BRUCKER AM-400 WB Spectrometer operating in the Fourier transform mode at a probe temperature of $300 \mathrm{~K}$. Chemicals shifts are given relative to sodium 2.2-dimethyl 2-silapentane 5-sulfonate (indirectly to acetone in $\mathrm{D}_{2} \mathrm{O}: \delta=2.225 \mathrm{ppm}$ ). Resolution enhancement of the ${ }^{1} \mathrm{H}$ NMR spectrum was achieved by Lorentzian-to-Gaussian transformation. Interpretation of the ${ }^{1} \mathrm{H}$ NMR spectrum was made according to Cohen and Ballou (3).

Construction and analysis of NGLO. Construction and analysis of NGLO were carried out according to a previously described method (6). Briefly, $100 \mathrm{mg}$ of 4-hexadecylaniline (Aldrich Chemical Co., Milwaukee, Wis.) was added to 500 $\mu$ l of a solution containing $35 \mathrm{mg}$ of sodium cyanoborohydride, $3.5 \mathrm{ml}$ of methanol, and $400 \mu \mathrm{l}$ of acetic acid. The solution was heated at $80^{\circ} \mathrm{C}$, and $1 \mathrm{mg}$ of O-linked oligomannosides solubilized in $50 \mu \mathrm{l}$ of water was added to $200 \mu \mathrm{l}$ of this solution and incubated at $80^{\circ} \mathrm{C}$ for $90 \mathrm{~min}$. The solution was cooled, mixed with chloroform and water added in equal parts, and centrifuged. The aqueous phase was dried, dissolved in methanol $(2 \mathrm{ml})$, and centrifuged. The supernatant containing the NGLO was conserved.

ELISA procedure. The ELISA involved PPM and NGLO coated onto 96-well polystyrene plates (Nunc Immuno Type II).

The method was set up, as previously described for a different pool of oligomannosides, by analyzing the reactivity of three patient sera with different IFA titers (5a). For given concentrations of human antibodies and conjugates, the elevation in optical density (OD) was related to the quantity of PPM and NGLO until a maximum was reached. We chose for both antigens the carbohydrate concentration giving the best discrimination between sera with different IFA titers. As before (5a), at these concentrations of antigen and neoantigen, reactions with antibodies were found as to be dose dependent and saturable.

Application of these analyses led to the definition of the following methods as routine procedures. They were used throughout the study.

For NGLO, each well received $50 \mu \mathrm{l}$ of a $10-\mu \mathrm{g} / \mathrm{ml}$ solution of antigen in carbonate buffer $(60 \mathrm{mM}, \mathrm{pH} \mathrm{9.6).}$ Plates were incubated for $1 \mathrm{~h}$ at $37^{\circ} \mathrm{C}$ and overnight at $4^{\circ} \mathrm{C}$ and then washed five times in TNT buffer (Tris, $50 \mathrm{mM}$; $\mathrm{NaCl}, 150 \mathrm{mM}$; $\mathrm{HCl}$ [pH 7.5]; Tween 20, 0.05\%). The last wash was prolonged for $5 \mathrm{~min}$. The plates were stored at $-20^{\circ} \mathrm{C}$. All wells were saturated with a bovine serum albumin (Boehringer, Mannheim, Germany) solution diluted to $3 \%$ in TNT buffer lacking Tween. $50-\mu$ l volume of $1 / 1,000$ serum diluted in TNT buffer was incubated in each well for $1 \mathrm{~h}$ at $37^{\circ} \mathrm{C}$. After four washes in TNT, $50 \mu \mathrm{l}$ of the peroxidase-labeled antibody (goat anti-human immunoglobulin IgG, IgM, and IgA [Biosoft, Paris, France, and Zymed Laboratories, South San Francisco, Calif.]) diluted in TNT $(1 / 2,000)$ was incubated for $1 \mathrm{~h}$ at $37^{\circ} \mathrm{C}$. After five washes in TNT buffer, each well received $100 \mu l$ of the enzymatic substrate via a solution of orthophenylenediamine at $1 \mathrm{~g} /$ liter in TNT buffer with $0.5 \mu$ l of hydrogen peroxide (30\%) per $\mathrm{ml}$. After $30 \mathrm{~min}$ of incubation at room temperature in the dark, the reaction was stopped by adding $50 \mu$ l of $4 \mathrm{M} \mathrm{H}_{2} \mathrm{SO}_{4}$. Plates were scanned at $490 \mathrm{~nm}$ on a microELISA reader. The

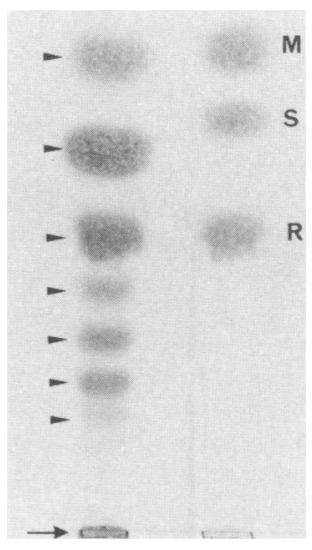

FIG. 1. Thin-layer chromatography of oligosaccharides released by alkaline degradation ( $\beta$ elimination) on PPM depleted in oligosaccharides linked through phosphodiester bonds by mild acid hydrolysis. Oligosaccharides were desorbed from a Bio-Gel P4 column $(1.8$ by $150 \mathrm{~cm})$. Seven spots, corresponding to oligosaccharides containing one to seven mannose residues, can be seen. Three controls were used: mannose (M), saccharose $(S)$, and raffinose (R). The arrow at the bottom indicates the point of application.

ELISA procedure using PPM antigen coated on ELISA plates was similar except that (i) plates were coated with 100 $\mu$ l of a $1-\mu \mathrm{g} / \mathrm{ml}$ solution of PPM, (ii) human sera $(100 \mu \mathrm{l})$ were used at a dilution of $1 / 8,000$, and (iii) peroxidase-labeled antibody $(100 \mu \mathrm{l})$ was used at a dilution of $1 / 1,000$.

Statistical analyses. Correlations between results obtained with all serological procedures on the 30 sera were studied after a variable transformation for variance homogeneity (27). The correlation coefficients were analyzed by the $t$ test (23).

\section{RESULTS}

Analysis of oligosaccharides released by mild alkaline degradation. Thin-layer chromatography of oligosaccharides released by $\beta$ elimination showed the presence of oligosaccharides with one to seven mannose residues (Fig. 1). The quantitatively major components were mannobiose and mannotriose.

${ }^{1} H$ NMR analysis of mannobiose and mannotriose. The NMR spectra of mannobiose and mannotriose (Fig. 2) were assigned by the method of Cohen and Ballou (3). For the mannobiose, the anomeric protons were observed at $\delta=$ $5.043 \mathrm{ppm}$ (terminal mannose B) and $5.378 \mathrm{ppm}$ (reducing mannose $\mathrm{A}, \alpha$ anomer) (Fig. 2A). The coupling constants were $1.8 \mathrm{~Hz}$ for $B$ and $A \alpha$ and $1.1 \mathrm{~Hz}$ for $A \beta$. For the mannotriose, the anomeric protons were found to resonate at $5.045 \mathrm{ppm}$ (terminal mannose C), $5.297 \mathrm{ppm}$ (internal mannose B), $5.368 \mathrm{ppm}$ (reducing mannose $\alpha$ ), and 4.911 (reducing mannose $\beta$ ) (Fig. 2B). The coupling constant observed for the $\mathrm{C}, \mathrm{B}$, and $\mathrm{A} \alpha$ signals was $1.8 \mathrm{~Hz}$, which confirms the $\alpha$ anomery. The results confirmed the structure of the two O-linked oligosaccharides as $\operatorname{Man}(\alpha 1-2)$ Man and $\operatorname{Man}(\alpha 1-2) \operatorname{Man}(\alpha 1-2) \operatorname{Man}$.

Analysis of NGL. The pool of NGLO was analyzed by thin-layer chromatography. Individual components were visualized either under UV light, according to their lipid moieties (Fig. 3), or after orcinol staining according to their carbohydrate moieties (data not shown). Seven bands were identified. They were interpreted as resulting from the migration of Mannose-4hexadecylaniline to Mannohexaose- 

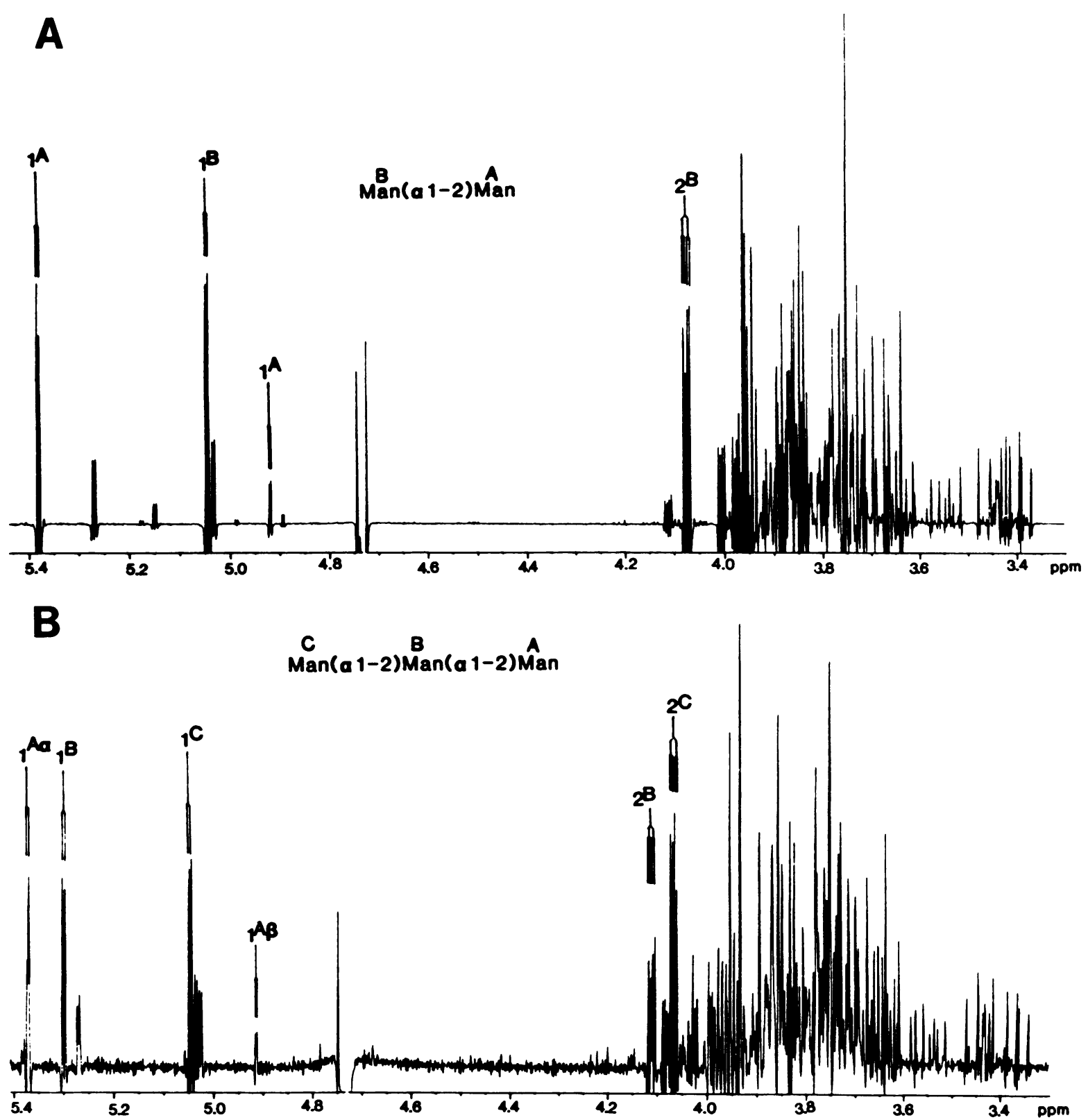

FIG. 2. ${ }^{1} \mathrm{H}$ NMR spectra of the two quantitavely major oligomannosides released from $C$. albicans after $\beta$ elimination: mannobiose (A) and mannotriose (B).

4hexadecylaniline, with two bands for the Mannobiose4hexadecylaniline.

Human humoral response against NGLO analyzed by ELISA. (i) Analysis of individual responses. When sera from individual patients were allowed to react against NGLO, seroconversion, as revealed against $C$. albicans antigens by the routine serological procedures (Table 1), corresponded to an increase of the ELISA signal against NGLO (Fig. 4). Strong differences were observed in the intensity of the ELISA signal between individual patients either before or after seroconversion. The OD for sera drawn before seroconversion were usually very low, ranging from 0.005 to 0.098, whereas the OD for sera taken after seroconversion ranged from 0.086 to 0.499 . The levels of both ELISA signals were apparently irrelevant to the mycological data. How- ever, an increase in OD against the neoantigen was systematically observed for any couple of sera, each patient being his own control, confirming the antigenicity of NGLO.

(ii) Statistical analyses of serological tests. Variable transformation for variance homogeneity in relation to IFA titers led us to express the results of all serological tests except Co-CIE by their logarithms. Linear regression analysis (Fig. 5) demonstrated the existence of a correlation between ELISA-NGLO and IFA (Fig. 5A), Co-CIE (Fig. 5B), and ELISA-PPM (Fig. 5C). The significance of all correlations was greater than 0.001 . The coefficient correlation squares were respectively $0.665,0.706$, and 0.718 , indicating that 66 , 70 , and $71 \%$ of variation in OD values against NGLO related to variations in serological tests involving "natural" $C$. albicans antigens. 


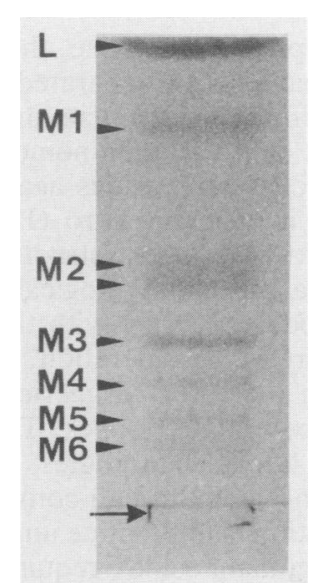

FIG. 3. Thin-layer chromatography of NGL constructed by coupling oligosaccharides released by $\beta$ elimination to the 4-hexadecylaniline. The NGL are revealed under UV light $(254 \mathrm{~nm})$ according to their lipid moiety. The arrow at the bottom indicates the point of application. Abbreviations: L, uncoupled lipid; coupled sugars mannose (M), mannobiose (M2), mannotriose (M3), mannotetraose (M4), mannopentose (M5), and mannohexaose (M6).

\section{DISCUSSION}

C. albicans cell wall PPM is a molecule which has been extensively studied from chemical $(12,14,24-26)$ and immunological $(4,5,7,8,18,28)$ points of view. The final goal of such studies is to define relationships between molecular structure and immunoreactivity. However, because of the lack of methodologies suitable for extensive screenings, no data are available concerning the molecular basis of human antibody response. Studies concerning the immunoreactivity of the C. albicans oligomannoside repertoire are presently restricted to antisera studied in highly specialized laboratories able to produce and analyze large quantities of oligomannosides (7). Faced with this problem, we have recently developed a method of construction of NGL from oligomannosides released by sequential depolymerization of the PPM. Such neoantigens have been shown in experimental models to exhibit immunogenicity and antigenicity (6), mimicking the activity of $C$. albicans natural antigens. NGL coated on ELISA plates have also been shown to react with mammalian polyclonal or monoclonal immunoglobulins reacting with the original PPM, according to dose-dependent and saturable reactions $(5 \mathrm{a})$.

In the present work, this method has been applied to the study of human antibodies able to react with the family of oligomannosides linked to the PPM molecule by $O$-glycoside linkages and released after $\beta$ elimination (16). Mild alkaline degradation of $C$. albicans mannan, previously depleted in oligomannosides attached through phosphodiester bonds, led to the release of O-linked oligomannosides containing one to seven mannose residues. The structural determination of the major oligomannosides, mannobiose and mannotriose, demonstrated the presence of $(\alpha 1-2)$ linkages. These results are similar to those obtained by Podzorski et al. with another C. albicans strain (18), except that those authors described only six oligomannosides. Thin-layer chromatography analysis of oligosaccharides after they were coupled to 4-hexadecylaniline allowed the efficiency of the binding to be visualized and assessed. Each coupled oligomannoside except the mannobiose appeared on the chromatogram as a single band; the mannobiose gave two bands. The most likely hypothesis to explain this observation would be related to the aglycone part of NGL, the aqueous solvent triggering two different ionizations. This phenomenon hap-

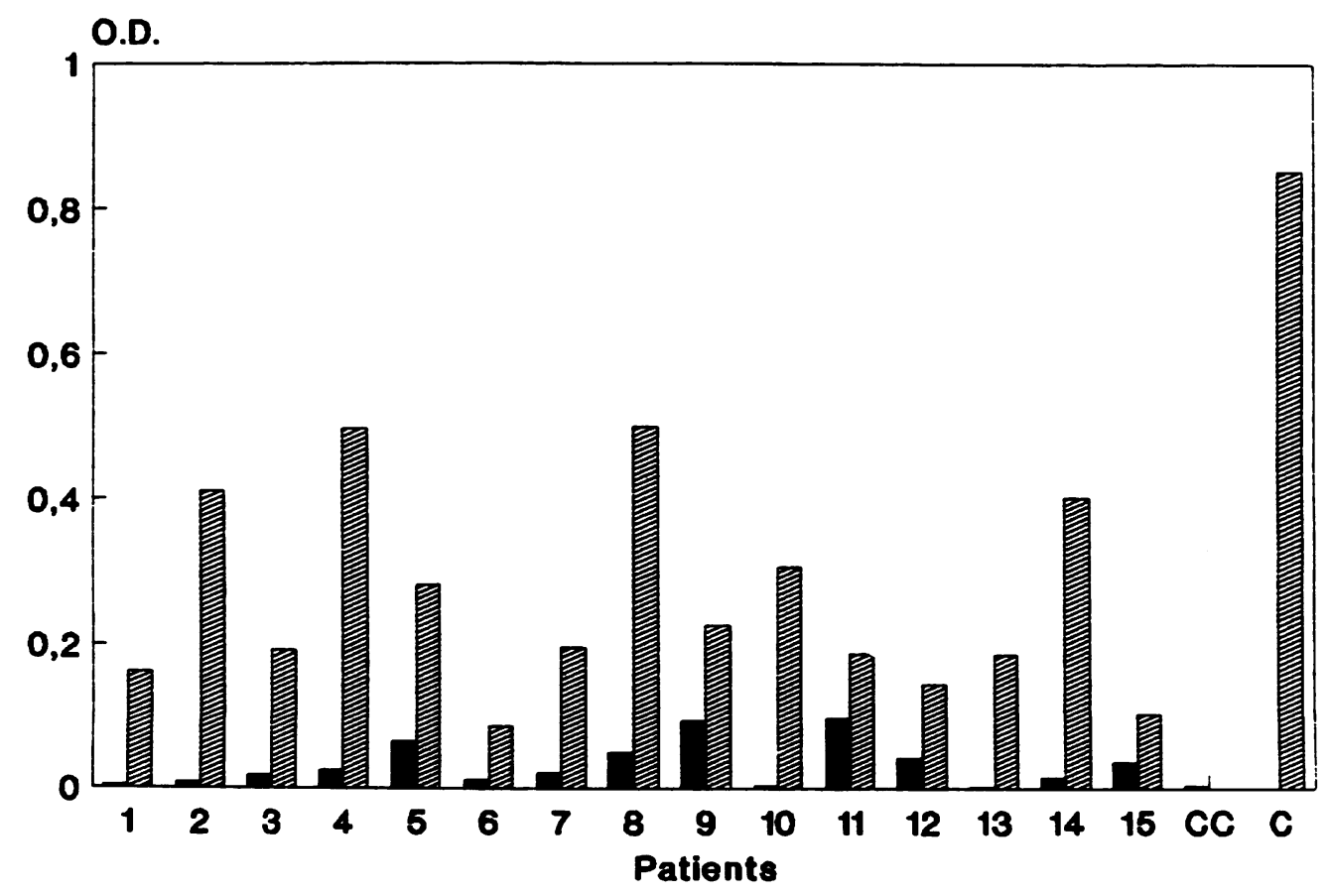

FIG. 4. Human serum reactivity against NGLO as analyzed by ELISA. Results are expressed as OD for each pair of sera drawn from the 15 selected patients. Sera drawn before seroconversion are represented by black bars, and sera drawn after seroconversion are represented by hatched bars. Numbers under the abscissa refer to patient numbers as identified in Table 1 . CC, conjugate control; C, positive serum control. 

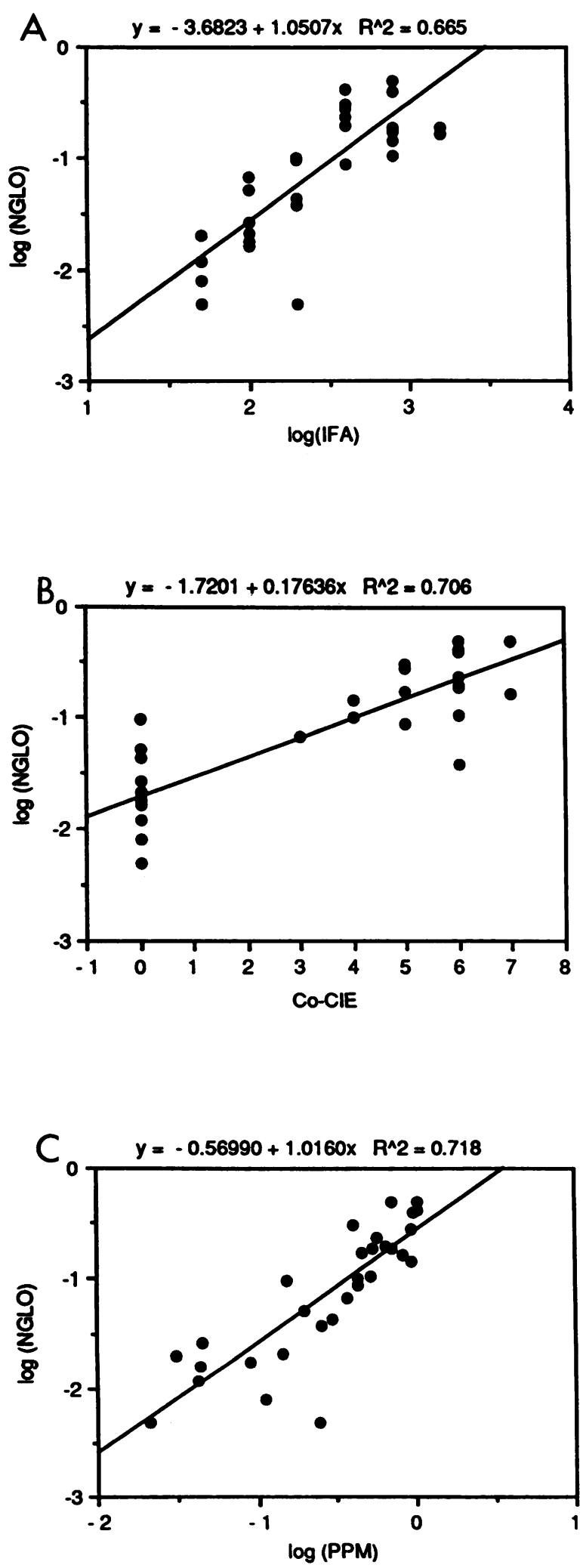

FIG. 5. The graphs represent the relations between serological results given by ELISA-NGLO and IFA (A) Co-CIE (B), and ELISA-PPM (C). All the data except those for Co-CIE were used after variable transformation. The curve's equations are noted on the top of each graph; $\mathbf{R} \hat{\mathbf{2}}$ is the coefficient correlation square relating the two variables. pened only for coupled mannobiose, the other oligommanosides being too heavy to be separated on thin-layer chromatograms according to their ionization patterns.

Despite the fact that an immunomodulatory role of $C$. albicans $\mathrm{O}$-linked oligomannosides against human lymphocytic proliferation induced in vitro (18) has been demonstrated, it was not known if these structures could react with antibodies. From a physiopathological point of view, the existence of antibodies reacting with these oligomannoside species is an important consideration, since the antibodies may interfere with the direct triggering of lymphoid cells induced by these potential epitopes. The demonstration of the existence of human antibodies able to react with O-linked oligomannosides through conventional methods of precipitation inhibition is in practice unrealizable because of the amount of oligomannosides required for such experiments $(7,17)$. Considering this lack of methodology adapted to extensive screenings of $C$. albicans oligomannoside reactivity with human and animal antibodies, we have recently developed a method for constructing NGL from these residues. Following application of this method, oligomannosides from various families $(5 a, 6)$ have been shown to bind to conventional substrates for immunoanalysis through their lipid carrier molecule and to be able to react with antibodies according to dose-dependent and saturable reactions (5a). Construction of NGL from $C$. albicans O-linked oligomannosides provided, for the first time, evidence of human antibodies reacting with these residues. Evidence came both from increased ELISA-NGLO signals following individual seroconversions and from the close correlation observed between reactivity of sera against NGLO and PPM. Despite individual differences, whose diagnostic and prognostic significance remains presently unclear, reactivity of patient sera against neoantigens evaluated as a whole did not significantly differ from that against the PPM from which the neoantigens were derived. These results are compatible with what is known about the structure of O-linked oligomannosides composed of Man $\alpha$ (1-2) and Man $\alpha$ (1-3) linkages largely distributed through the N-linked part of the PPM molecule (24); in the same way, the use of PPM depleted in O-linked oligomannosides did not significantly affect PPM reactivity against patient sera (unpublished data). It is also consistent with the experimental evidence reported by Shibata et al. (26) that, in contrast to mild acid hydrolysis, $\beta$ elimination did not affect the precipitating effect of antibodies raised against different $C$. albicans serotypes. Therefore, according to this lack of structural specificity of $C$. albicans O-linked oligomannosides, it is impossible at the present stage of this work to say if the antibody response demonstrated here resulted from specific triggering of the human immune system by these molecules or represented crossreactivity with antibodies generated against similar structures by other oligomannoside species of the mannan molecule.

The acknowledged risk of our immunochemical approach, which also exists with the precipitation inhibition reactions in liquid phase used as a reference (7), is that neoantigens could suffer chemical alterations during preparation procedures so that their conformation would not mimic the natural antigen. In this respect, the correlation observed between the ELISA-PPM and ELISA-NGLO has been encouraging. As an incidental finding, statistical analysis revealed no interference between the results obtained and antigenemia, as revealed by the Cand-tec test (9) in sera from 12 patients (data not shown). Despite slight differences between individual antibody detection tests which appeared when the tests 
were compared two by two after an adapted variable transformation, a good overall correlation was nevertheless observed between them. This is not surprising, since all these tests detect antibodies against $C$. albicans mannoproteins according to their precipitation with a whole-cell extract (20), their reactivity with the cell wall surface (22), or their reactivity with the PPM extracted from the surface and deeper layers of the cell wall (21). Construction of NGL therefore provides a way for the determination of the molecular basis of the human antibody response against cell wall mannan, which has so far been appreciated as a whole. This analysis is currently being extended to other oligomannoside families to determine the prognosis and diagnostic significance of their recognition by human immunoglobulin isotypes.

\section{ACKNOWLEDGMENTS}

This work was supported by the Institut National de la Santé et de la Recherche Médicale, the Centre National de la Recherche Scientifique (CNRS, Unité mixte 111; Relations structure-fonction des constituants membranaires; Directeur, J. Montreuil), and the Fondation pour la Recherche médicale.

We are grateful to J. M. Wieruszelski for recording the NMR spectra and to G. Lepage and A. Bernigaud for their valuable technical assistance.

\section{REFERENCES}

1. Bailey, J. W., E. Sada, C. Brass, and J. E. Bennett. 1985. Diagnosis of systemic candidiasis by latex agglutination for serum antigen. J. Clin. Microbiol. 21:749-752.

2. Chew, W. H., and T. L. Theus. 1967. Candida precipitins. J. Immunol. 98:220-224.

3. Cohen, R. E., and C. E. Ballou. 1980. Linkage and sequence analysis of mannose-rich glycoprotein core oligosaccharides by proton nuclear magnetic resonance spectroscopy. Biochemistry 14:4345-4358.

4. Domer, J. 1989. Candida cell wall mannan: a polysaccharide with diverse immunologic properties. Crit. Rev. Microbiol. 17:33-51.

5. Durandy, A., A. Fischer, D. Charron, and C. Griscelli. 1986. Specific binding of antigen onto human T lymphocytes. J. Clin. Invest. 77:1577-1587.

5a.Faille, C. Submitted for publication.

6. Faille, C., J. C. Michalski, G. Strecker, D. W. R. Mackenzie, D. Camus, and D. Poulain. 1990. Immunoreactivity of neoglycolipids constructed from oligomannosidic residues of the Candida albicans cell wall. Infect. Immun. 58:3537-3544.

7. Fukazawa, Y. 1989. Antigenic structure of Candida albicans, p. 37-62. In E. Kurstak, G. Marquis, P. Auger, L. de Repentigny, and S. Montplaisir (ed.), Immunology of fungal diseases. Marcel Dekker, Inc., New York.

8. Fukazawa, Y., A. Nishikawa, M. Suzuki, and T. Shinoda. 1980. Immunochemical basis of the specificity of the yeast: immunochemical determinants of several antigenic factors of yeasts, $p$. 126-136. In H. J. Preusser (ed.), Medical mycology. G. Fisher, Stuttgart, Germany.

9. Gentry, L. O., I. D. Wilkinson, A. S. Lea, and M. F. Price. 1983. Latex agglutination test for detection of Candida antigen in patients with disseminated disease. Eur. J. Clin. Microbiol. 2:122-128.

10. Georges, E., M. L. Garrigues, J. L. Poirot, J. P. Massini, and M. C. Meyohas. 1991. Diagnostic des candidoses systémiques par un test au latex. Résultats d'une année de suivi sérologique chez les malades à risques. J. Mycol. Med. 118:25-28.

11. Hasenclever, H. F., and W. O. Mitchell. 1961. Antigenic studies of Candida. Observation of two antigenic groups in Candida albicans. J. Bacteriol. 82:570-573.
12. Kobayashi, H., N. Shibata, H. Mittobe, Y. Okubo, and S. Suzuki. 1989. Structural study of phosphopeptidomannan of yeast-form cells of Candida albicans J-1012 strain, with special reference to application of mild acetolysis. Arch. Biochem. Biophys. 72:364 375 .

13. Kocourek, J., and C. E. Ballou. 1969. Method for fingerprinting yeast cell wall mannans. J. Bacteriol. 100:1175-1180.

14. Kogan, G., V. Pavliak, and L. Masler. 1988. Structural studies of mannan of the cell wall of pathogenic yeast Candida albicans serotypes A and B and Candida parapsilosis. Carbohydr. Res. 172:243-253.

15. Lehman, P. F., and E. Reiss. 1980. Comparison by ELISA of serum anti-Candida albicans mannan IgG levels of normal population and in diseased patients. Mycopathology 70:89-93.

16. Nakajima, T., and C. E. Ballou. 1974. Characterization of the carbohydrate fragments obtained from Saccharomyces cerevisiae mannan by alkaline degradation. J. Biol. Chem. 249:76797684.

17. Okubo, Y., T. Ichikaya, and S. Suzuki. 1978. Relationship between phosphate content and immunochemical properties of subfractions of baker's yeast mannan. J. Bacteriol. 136:63-68.

18. Podzorski, R. P., G. R. Gray, and R. D. Nelson. 1990. Different effects of Candida albicans mannan and mannan-derived oligosaccharides on antigen-stimulated lymphoproliferation in vitro. J. Immunol. 144:707-716.

19. Poulain, D., A. Ayadi, and J. Fruit. 1987. Détection d'un antigène témoin d'infection systémique à Candida à l'aide d'un anticorps monoclonal couplé à l'or colloïdal. Ann. Biol. Clin. 45:565-577.

20. Poulain, D., J. Fruit, L. Fournier, E. Dei Cas, and A. Vernes. 1986. Application of co-counterimmunoelectrophoresis to the diagnosis of systemic candidiasis. Importance and limitation of the method. Eur. J. Clin. Microbiol. 5:427-434.

21. Poulain, D., V. Hopwood, and A. Vernes. 1985. Antigenic variability of Candida albicans. Crit. Rev. Microbiol. 12:223270.

22. Poulain, D., G. Tronchin, J. F. Dubremetz, and J. Biguet. 1978. Ultrastructure of the cell wall of Candida albicans blastospores: study of its constitutive layers by the use of a cytochemical technique revealing polysaccharides. Ann. Microbiol. (Inst. Pasteur) 129:141-153.

23. Schwartz, D. 1989. Test d'indépendance entre deux variables quantitatives, p. 207-223. In Flammarion (ed.), Méthodes statistiques à l'usage des médecins et des biologistes, 9ème ed., Imprimerie Nouvelle, Saint-Jean-de-Braye, France.

24. Shibata, N., S. Fukazawa, H. Kobayashi, M. Tojo, T. Yonezu, A. Ambo, Y. Ohkubo, and S. Suzuki. 1989. Structural analysis of phospho-D-peptidomannan-protein complexes isolated from yeast and mold form cells of Candida albicans NIH A-207 serotype A strain. Carbohydr. Res. 187:239-253.

25. Shibata, N., T. Ichikawa, M. Tojo, M. Takahashi, N. Ito, Y. Okuo, and S. Suzuki. 1985. Immunochemical study on the mannan of Candida albicans NIH A-207, NIH B-792 and J-1012 strains prepared by fractional precipitation with cetyltrimethylammonium bromide. Arch. Biochem. Biophys. 243:338-348.

26. Shibata, N., H. Kobayashi, M. Tojo, and S. Suzuki. 1986. Characterization of phosphopeptidomannan-protein complexes isolated from viable cells of yeasts and mycelial forms of Candida albicans NIH B-792 strain by the action of zymolyase 100-T. Arch. Biochem. Biophys. 251:697-708.

27. Snedecor, G. W., and W. G. Cochran. 1967. Statistical methods, 6th ed., p. 325-330. Iowa State University Press, Ames.

28. Suzuki, M., and Y. Fuzakawa. 1982. Immunochemical characterization of Candida albicans cell wall antigens: specific determinant of Candida albicans serotype A mannan. Microbiol. Immunol. 26:387-409.

29. Tsuchiya, T., Y. Fukazawa, M. Tagushi, T. Kase, and T. Shinoda. 1974. Serologic aspects on yeast classification. Mycopathol. Mycol. Appl. 53:77-85. 